\title{
An Improved Method for Determining the Vertical Ozone Distribution Using Satellite Measurements
}

\author{
Tadashi Aruga ${ }^{1}$ and Donald F. Heath ${ }^{2}$ \\ 'Communications Research Laboratory, Ministry of Posts and Telecommunications, \\ Koganei, Tokyo 184, Japan \\ ${ }^{2}$ NASA Goddard Space Flight Center, Greenbelt, Maryland 20771, U.S.A.
}

(Received March 30, 1988; Revised June 29, 1988)

\begin{abstract}
This paper will discuss an improved method for determination of vertical ozone distributions from spectral measurements of ultraviolet radiances diffusely reflected from the terrestrial atmosphere. A new inversion method previously presented has been improved, where the effects of multiple scattering and the lower boundary of the atmosphere (ground surface or cloud-top) are incorporated into the inversion procedure. Error bars on the retrieved ozone profiles are also taken into account. The improved inversion algorithm was tested using data of NIMBUS 4 backscattered ultraviolet (BUV) experiments. There is very good agreement between the vertical distributions from observations made from the satellite platform and those made from coincident rocket soundings. The results indicate that the vertical distributions of atmospheric ozone can be obtained by the improved method with high accuracy over a wide range of altitude.

For the future BUV satellite observation, the weighting function has been analyzed from some points of view, then an optimum selection of wavelengths is presented as a result of the weighting function analyses. Furthermore, the use of logarithmically defined parameter of ozone increment is recommended for expanding a dynamic range of the inversion.
\end{abstract}

\section{Introduction}

It is well known that ozone in the stratosphere plays an important role in heating and dynamical processes through its absorption of ultraviolet solar radiation and that its stability is being threatened by man's activities. Its precise role as the most important trace constituent in the middle atmosphere cannot be determined without accurate global scale observations over extended periods of many years.

The use of satellites as observational platforms for remotely sensing atmospheric parameters permits one to study the atmosphere in a way which is not practical from the ground. Remote sensing of the vertical distributions of some physical quantities such as temperature and concentration of trace species from satellites is effected by solving the so-called inverse problem. Two wavelength 
regions, infrared and ultraviolet can be used to infer atmospheric ozone distributions from satellite nadir measurements. The technique utilizing infrared atmospheric radiances has been developed and used by PRABHAKARA (1969) and CONRATH et al. (1970). The use of atmospheric backscattered ultraviolet (BUV) was developed by Singer and WENTWORTH (1957) and TWOMEY (1961). Methods for solving these kinds of inversion equations were also developed by TWOMEY (1965), CHAHine (1970), SMITH (1970) and MATEER (1972). Initial applications of the method to satellite observations have been reported by IOZENAS (1968), ANDERSON et al. (1969), and YARGER (1970). Subsequent work in this area has been reported by HEATH et al. $(1973,1975)$ and LONDON et al. (1977), using the spectral radiance data from NIMBUS 4 and OGO satellites, respectively. Determination of total ozone content by the use of BUV has been developed by DAVE and MATEER (1967) and HEATH et al. (1975).

In most methods, the total ozone content above a pressure level or pressure increment in a sub-layer has been used as the parameter of inversion. This is true for the Laplace transform method (TwOMEY, 1961; IOZENAS, 1968) and Pressure Increment (PI) method (YARGER, 1970). The former method is useful for retrieval of the upper level exponential ozone profile, while the latter provides higher accuracy when used to retrieve the lower level profile. These two methods were jointly used for inferring ozone profiles from some NIMBUS 4's BUV observations (KRUEGER et al., 1973). In the usual methods, the columnar ozone amount above certain layers are computed as a function of the pressure level. Ozone partial pressure data are, then, computed at each altitude by differentiating these columnar results with respect to altitude. The ozone profile obtained by this algorithm often contains large errors, since in general the differentiation enlarges the error. This is particularly significant when the magnitude of column content error becomes comparable to the magnitude of ozone content at each altitude.

Mateer presented an useful algorithm (MATEER, 1972) which is called the partial derivative (PD) method on the basis of algorithm of Umkehr measurements. Although the columnar ozone amount above a pressure level is treated as a parameter in the PD method, the use of partial derivative corresponds to that of the amount of ozone in each sub-layer. By combining an optimum statistical technique (RODGERS, 1976) with the PD method, the SBUV data have been analized. The details are shown in the User's Guide (FLEIG et al., 1982) and it's references. The reason why several inversion methods have been proposed, is the inversion problem for inferring atmospheric structures such as the vertical profiles of ozone corresponds to the solution of integral equation of the Fredholm 1st kind, and that this is difficult since the solution is generally unstable.

A new inversion method was also presented by the author (ARUGA and IGARASHI, 1976), which permits a computationally efficient retrieval of vertical ozone profiles with high accuracy over a wide altitude range, and is thus suitable for a global determination of ozone from satellite observations. The features of this method are as follows: The relative increment of ozone number density in each sublayer is used as the independent parameter. The weighting function is obtained in 
terms of the sensitivity, i.e., the radiance change in a wavelength channel affected by the relative increment of ozone number density at a height. Then, the inversion equation is formulated based on a principle that a radiance change at a wavelength is approximately equal to the sum of sensitivity multiplied ozone increment which are due to all sublayers (the effective sublayers are limited in a narrow altitude region as shown by the weighting function layer). A normalized weighting function is used in the inversion equation and it is assumed that probability of change of relative ozone content is equal at all altitudes. The inversion equation is solved by an iteration technique in which the solution is stable. The total ozone content also yields as the sum of ozone number density over all sublayers. It is to be noted that a precise formulation of radiative transfer to this inversion method is also presented in this previous paper.

The original method, however, includes exact calculation up to second order scattering in the inversion. This requires a large amount of computer time. In this work, the method is improved in such a way that the radiances and weighting functions in the inversion equation are corrected by multiple scattering coefficients calculated beforehand, in which the effects of the lower boundary (cloud-top or ground surface), as well as multiple scattering, are taken into account (ARUGA and HEATH, 1978, 1982a). The importance of the correction for the multiple scattering is shown as an ozone profile in Fig. 13 of the reference (ARUGA and HEATH, 1982a). In the improved method, one can correct these complicated effects by a simple equation shown later. Furthermore, error analyses are included both in the inversion equations and on the ozone profiles obtained with error bars, i.e., one can easily estimate the error of retrieved ozone profiles.

The principle of this inversion method was applied to other problems such as a limb-scan technique and very good results were obtained (ARUGA and HEATH, 1982b), which shows a wide applicability of this algorithm.

Recently the so-called ozone hole, i.e., a great decrease of the total column amount of ozone in Antarctic early spring has been found out by FARMAN et al. (1985) from the measurements in Antarctica, and also from the NIMBUS 7 satellite measurements (STOLARSKi et al., 1986). Due to the problem of ozone hole, the atmospheric ozone has again become a topic and importance of precise and longterm observation is newly recognized.

In this paper, we show the improved inversion method of inferring vertical ozone distributions, and validity of this method is demonstrated.

2. Principle of the Improved Inversion Method

\subsection{Inversion equation}

In this section, the principle of the inversion technique is described briefly. Assume $x$ to be the vertical coordinate and consider a set of $m$ wavelength, $\lambda_{1}, \lambda_{2}, \ldots, \lambda_{m}$ and define $F_{i}$ for the $i$-th wavelength $\lambda_{i}$ as follows:

$$
F_{i}=I\left(\lambda_{i}\right)-\bar{I}\left(\lambda_{i}\right), \quad i=1,2, \ldots, m,
$$


where $\bar{I}\left(\lambda_{i}\right)$ is the diffusely reflected (backscattered) radiant intensity calculated with an assumed ozone distribution $\bar{N}(x)$, and $I\left(\lambda_{i}\right)$ is the measured intensity. The ozone layer is divided into $n$ sublayers and we define $\bar{N}[j], N[j]$ to be the average ozone number density in the $j$-th layer for the assumed distribution (indicated by a bar over the quantity) and actual (to be determined), respectively, and define $y_{j}$ as follows:

$$
y_{j}=\frac{N[j]-\bar{N}[j]}{\bar{N}[j]},
$$

or

$$
N[j]=\bar{N}[j]\left(1+y_{j}\right), \quad j=1,2, \ldots, n .
$$

The next equation (1st order approximation in Talor expansion) holds well for a wide $y_{j}$,

$$
F_{i}=\sum_{j=1}^{n} D_{i j} y_{j}, \quad i=1,2, \ldots, m
$$

where

$$
D_{i j}=\left(\frac{\mathrm{d} F_{i}\left(y_{j}\right)}{\mathrm{d} y_{j}}\right)_{y_{j}=0}, \quad\left\{\begin{array}{l}
i=1,2, \ldots, m \\
j=1,2, \ldots, n
\end{array}\right.
$$

The quantity $F_{i}\left(y_{j}\right)$ means a partial $F_{i}$, i.e., the difference of radiances $I^{*}\left(\lambda_{i}\right)$ and $\bar{I}\left(\lambda_{i}\right)$ respectively for hypothetic ozone distributions of $N^{*}[j]$ (ozone number density is $N[j]$ only in $j$-th layer keeping $\bar{N}[j]$ in other layers), and $\bar{N}[j]$. For details of the derivation of this inversion equation, one can refer ARUGA and IGARASHI (1976) and ARUGA and HEATH (1982b).

The parameter $y_{j}$ is obtained by solving the inversion equation using an iteration technique (see ARUGA and IGARASHI, 1976), then ozone number density $N[j]$ is calculated over $n$ sublayers. The multiple-scattering correction (for details, see ARUGA and HEATH, 1982a) for calculated radiant intensity $\bar{I}$ is done by the use of the multiple scattering coefficient $C_{\mathrm{m}}$ (see Appendix) as follows:

$$
\bar{I}=\bar{I}_{1}\left(1+C_{\mathrm{m}}\right)
$$

where $\bar{I}_{1}$ and $\bar{I}$ mean the radiance by single scattering and total scattering, respectively. The differential coefficient (sensitivity) $D_{i j}$ is also corrected by the use of $C_{\mathrm{m}}$ as

$$
D_{i j}=D_{i j}(1)\left(1+C_{\mathrm{m}}\right),
$$


where $D_{i j}(1)$ denotes that part of $D_{i j}$ due to single scattering.

The relative error of ozone number density in $j$-th layer obtained by this iteration method is estimated as follows. The relative error in the ozone number density $\delta N[j]$ is replaced by $\Delta y_{j}$, the absolute error of $y_{j}$ from Eq. (2). The error $\Delta y_{j}$ is expressed as

$$
\Delta y_{j}=\frac{\sum_{i=1}^{m}\left(E_{i} \delta F_{i}\right) P_{i j}}{\sum_{i=1}^{m} P_{i j}}, \quad j=1,2, \ldots, n
$$

using the equations (12)-(15) of ARUGA and IGARASHI (1976). Where $P_{i j}$ is the normalized weight (or probability) defined in the above reference, $E_{i}$ is a coefficient by which the relative radiant error $\delta F_{i}\left(=\Delta F_{i} / \bar{I}\left(\lambda_{i}\right)\right)$ is transferred to the error $\Delta y_{j}$, and expressed as

$$
E_{i}=\frac{\bar{I}\left(\lambda_{i}\right)}{\sum_{j=1}^{n} D_{i j}}, \quad i=1,2, \ldots, m
$$

The relative radiant error $\delta F_{i}$ (distinguished from absolute radiant error $\Delta F_{i}$ ) consists of the experimental error $\delta_{\mathrm{e}}$ and the theoretical error $\delta_{\mathrm{t}}$ as

$$
\delta F_{i}=\delta_{\mathrm{e}}+\delta_{\mathrm{t}}, \quad i=1,2, \ldots, m .
$$

The latter error $\delta_{\mathrm{t}}$ consists of the residual $R_{i}$ defined by ARUGA and IGARASHI (1976), and other theoretical errors which affect the calculated radiance $\bar{I}\left(\lambda_{i}\right)$. Equations (8)-(10) can be used for the altitude region between the peaks of weighting functions for the shortest and the longest wavelengths. The errors $\Delta y_{j}$ outside of the region, i.e., upper part and lower part, are estimated by using the feature that $\Delta y_{j}$ is inversely proportional to

$$
\sum_{j=1}^{m} P_{i j}
$$

\subsection{Weighting functions}

The so called contribution function is a kind of weighting function corresponding to columnar amount but not true weighting function which corresponds to ozone density at each altitude or ozone profile, since the content derived from differentiation of columnar density is not a true independent parameter. In the introduction it was stated that the weighting functions of the new method are obtained by calculating the sensitivity of relative increment of ozone number density of each layer to radiance increment in each wavelength. This value is a true independent parameter. 


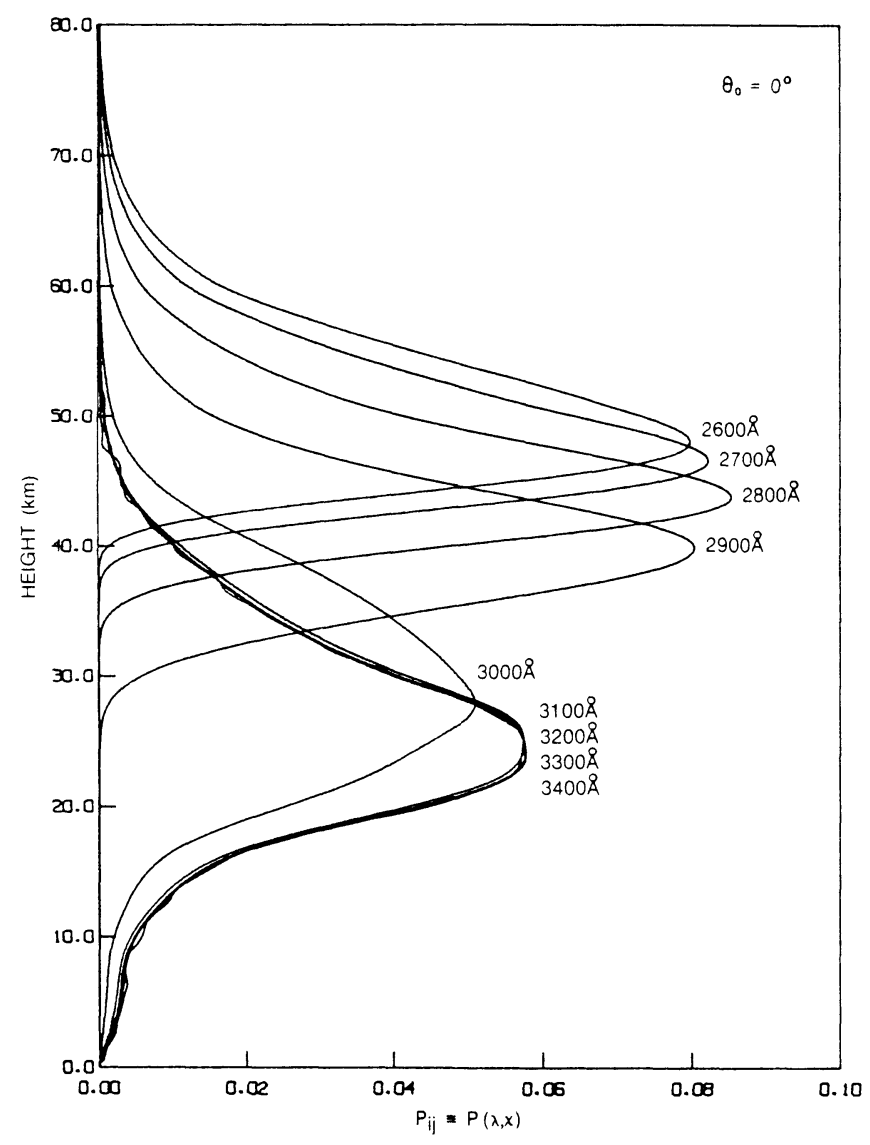

(a)

Fig. 1. Weighting functions of the new inversion method for the wavelengths from $2600 \AA$ to $3400 \AA$ by $100 \AA$ interval. Observations direction is assumed to be nadir $\left(\theta=0^{\circ}\right)$ and solar zenith angles are (a) $\theta_{0}=0^{\circ}$, (b) $\theta_{0}=60^{\circ}$, (c) $\theta_{0}=85^{\circ}$

In this section the weighting function of the new inversion method is discussed. Some examples of the weighting functions are shown in Figs. 1(a), (b), and (c). These were obtained by the use of middle latitude standard profiles shown in Fig. 2. The standard profiles in Fig. 2 are referred to HiLSENRATH et al. (1977). Wavelengths from $2600 \AA$ to $3400 \AA$ are used for the example shown in Fig. 1. The weighting functions for solar zenith angles $0^{\circ}, 60^{\circ}, 85^{\circ}$, are shown in Figs. 1(a), (b), and (c), where the instrument views the satellite nadir point, as in the case of the BUV experiment on NIMBUS 4. Observations in the nadir direction are assumed throughout this paper. These figures clearly show that a kind of saturation typically occurs at wavelengths of about $3100 \AA$ for small or medium solar zenith angles. One cannot obtain any significant information on the ozone distribution at lower 


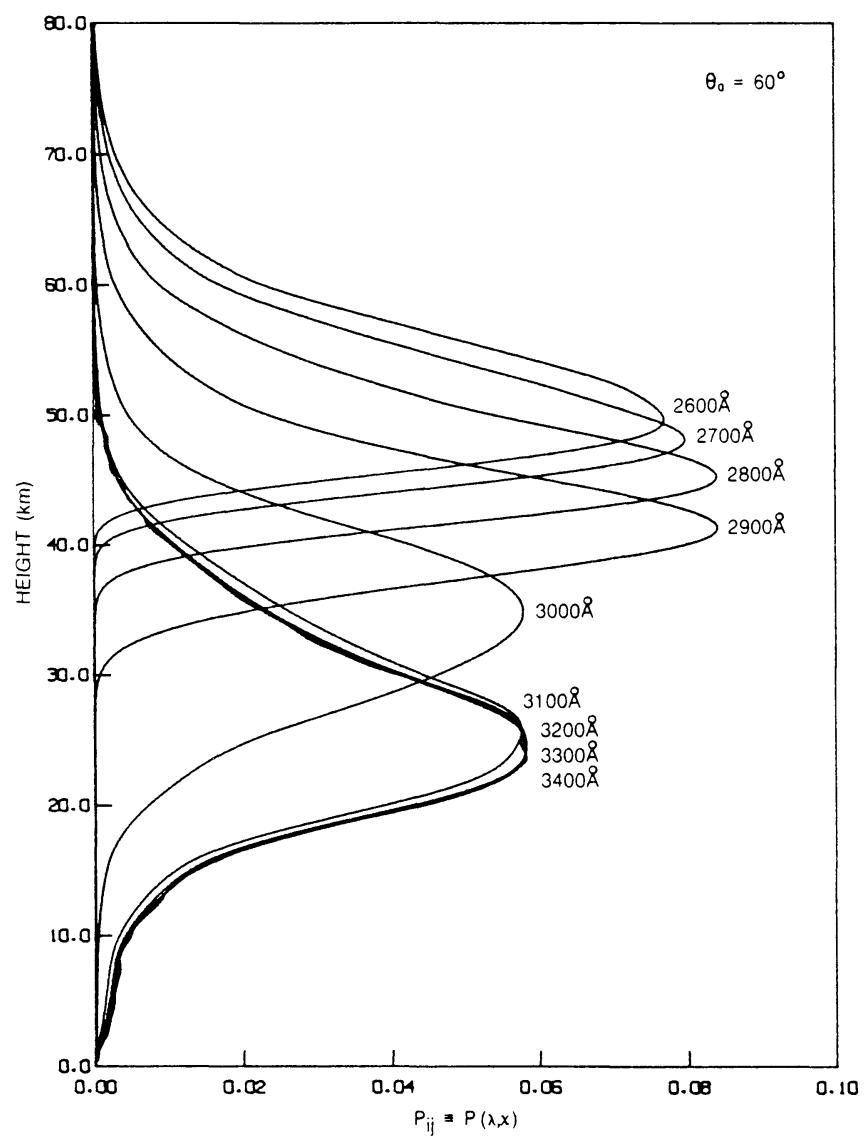

(b)

Fig. 1. (continued).

altitudes by going to longer wavelengths beyond $3100 \AA$. The use of longer wavelength is of significant value only for very large solar zenith angles as seen in the weighting function shown in Fig. 1(c). As the solar zenith angle increases the altitude of the peak of the weighting functions increases also. In the vicinity of the terminator radiance measured at wavelengths up to $3300 \AA$ does provide useful scientific information on the vertical distribution of ozone.

The weighting functions for the BUV experiment on NIMBUS 4 are shown in Fig. 3 for the solar zenith angle of $60^{\circ}$. Only the shortest eight wavelengths for the BUV experiment are shown, for the reason mentioned above.

The number of wavelength, $m$ used for the inversion, is selected to be eight $(m=8)$. This selection results from empirical one where optimum retrieval can be 


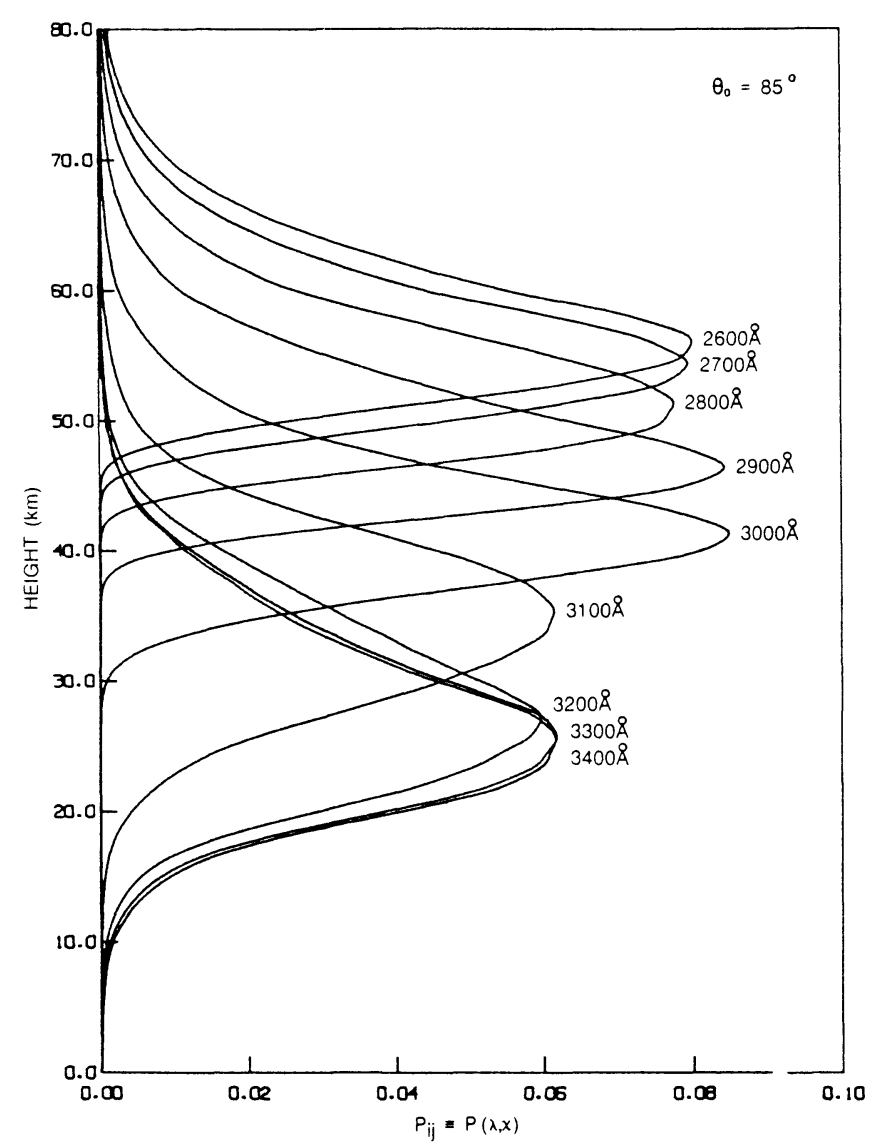

(c)

Fig. 1. (continued).

obtained in terms of computer time as well as ozone profile's accuracy. On the other hand, the number $n$ is selected with $1 \mathrm{~km}$ interval in this work. It should be noted that $1 \mathrm{~km}$ is not the resolution of the inversion. The vertical/altitude resolution of the inversion is about the same scale of width of the weighting function.

3. Test of the Inversion Method Using Satellite Data

3.1 Inferred vertical ozone distributions and comparison with coincident rocket soundings

When we solved the inversion equation by the iteration technique mentioned above, the standard ozone profiles shown in Fig. 2 were used as the initial guess. The 


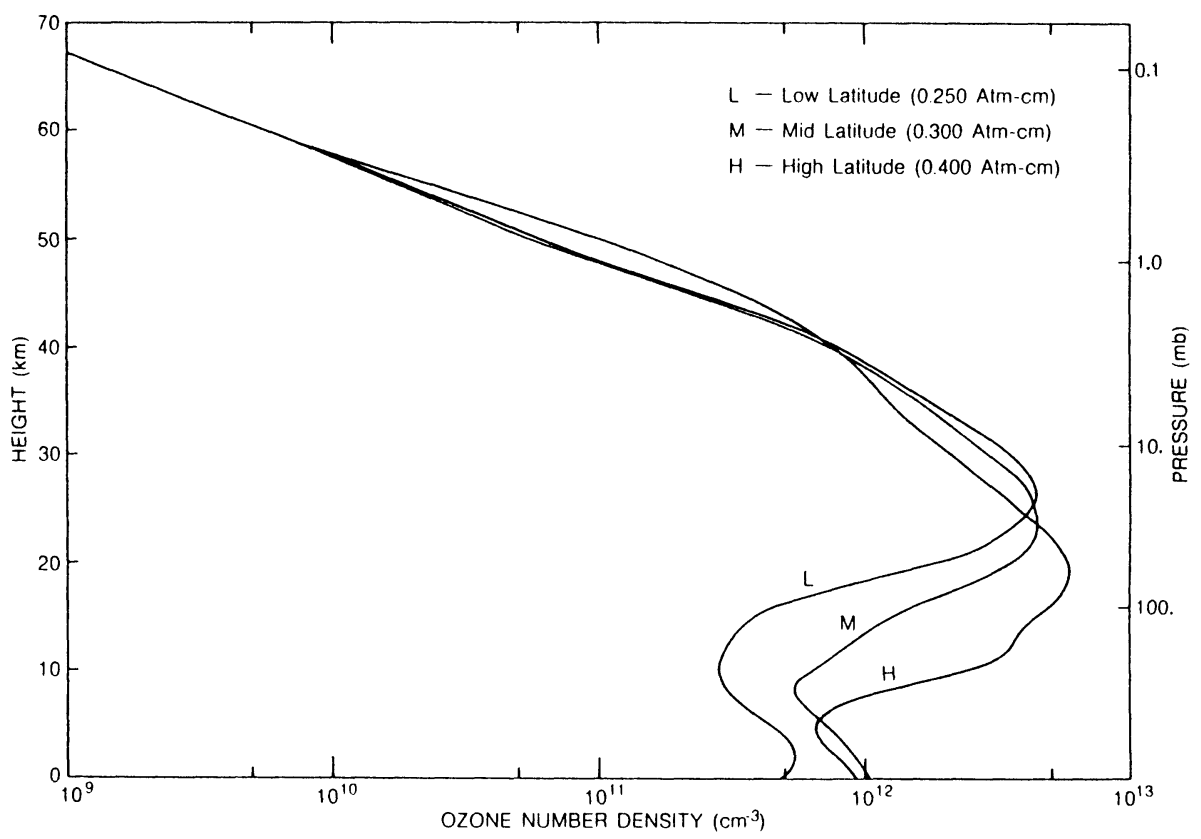

Fig. 2. Three ozone vertical profiles of low, middle and high latitudes, which were used for first guesses in this work. The three profiles were referred to the standard ozone profiles (HILSENRATH, 1977).

Rayleigh scattering cross section of air molecules, $\sigma_{\text {air }}$, ozone absorption cross sections $\sigma_{\text {ozone }}$ and the solar irradiance $J$ observed on NIMBUS 4 are shown in Table 1. The 1st channel $2555 \AA$ was not used because it might be affected by the NO molecule's $\gamma$ band emission.

Vertical distributions of ozone were inferred from observations of the BUV experiment on the NIMBUS 4 satellite and were compared with the ozone profiles obtained with rocket optical ozonesondes which were launched coincident in space and time with satellite overpasses (KRUEGER, 1973). It is to be noted that the weighting functions are calculated in each stage of iteration since they depend on ozone profile. Comparisons at four stations, Point Mugu $\left(33.9^{\circ} \mathrm{N}\right)$, Primrose $\left(54.6^{\circ} \mathrm{N}\right)$, Panama $\left(9.7^{\circ} \mathrm{N}\right)$, and Barking Sands $\left(22.7^{\circ} \mathrm{N}\right)$ are shown in Figs. $4(\mathrm{a}),(\mathrm{b})$, (c), and (d) in terms of ozone number density, and Figs. 5(a), (b), (c), and (d) in terms of ozone mixing ratio, respectively. The standard profiles $\mathrm{L}$ and $\mathrm{M}$ in Fig. 2 were used as initial guesses for the Panama and Primrose stations, respectively. For the Point Mugu and Barking Sands stations, an average profile of $L$ and $M$ was used. The multiple-scattering coefficient $C_{\mathrm{m}}$ was referred to the previously calculated table (see Appendix) and interpolated for each parameters. For this calculation, the U. S. standard atmosphere and aerosol distributions from the Elterman model were used (VALLEY, 1965) and the lower boundary reflectivity (or albedo) A was determined from a channel at $3800 \AA$. These are shown in Table 2 . The solar zenith 


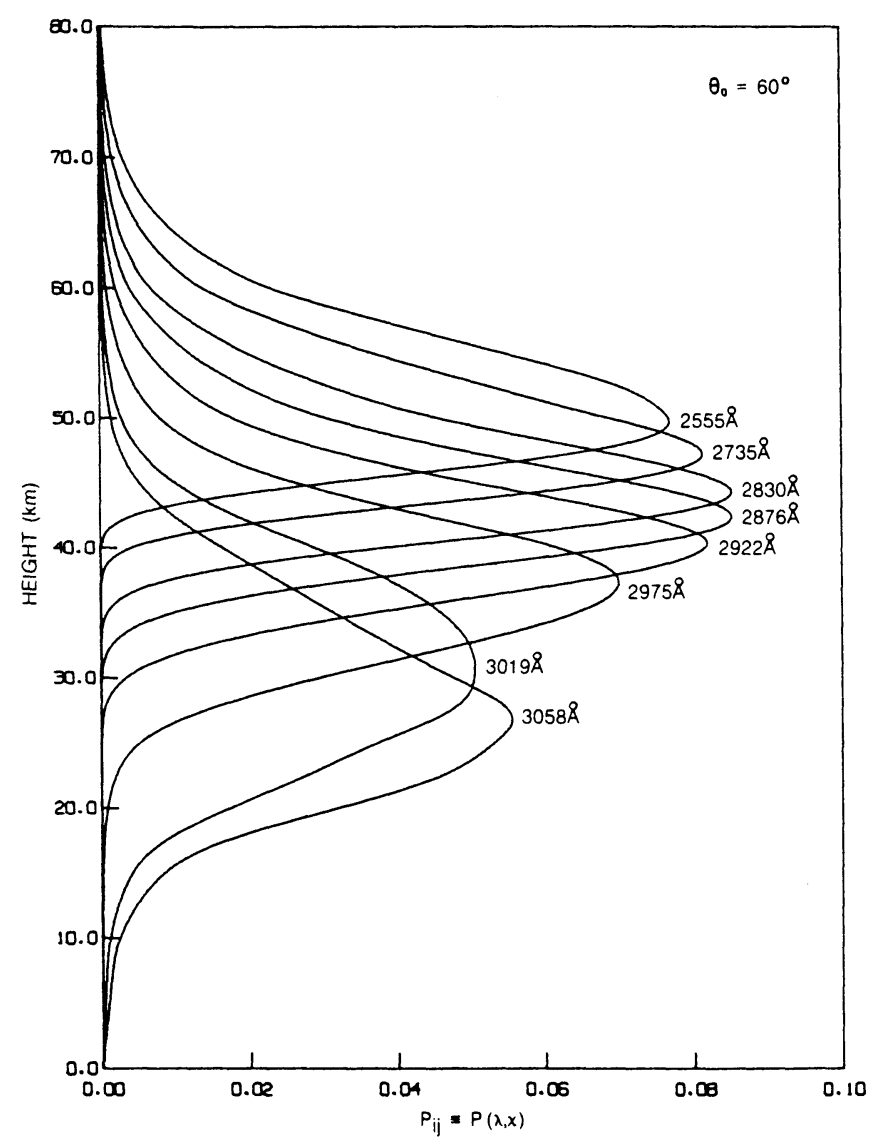

Fig. 3. Weighting functions of the inversion method for the wavelengths which were used in NIMBUS $4 \mathrm{BUV}$ experiments. Solar zenith angles $\theta_{0}=60^{\circ}$ is assumed here.

Table 1. Solar irradiance, Rayleigh scattering cross section and ozone molecule absorption cross section.

\begin{tabular}{cccc}
\hline$(\AA)$ & $J\left(\mathrm{erg} \mathrm{sec}^{-1} \mathrm{~cm}^{-2} \AA^{-1}\right)$ & $\sigma_{\text {air }}\left(\mathrm{cm}^{2}\right)$ & $\sigma_{\text {ozone }}\left(\mathrm{cm}^{2}\right)$ \\
\hline 2555 & 11.22 & $1.142 \times 10^{-25}$ & $1.108 \times 10^{-17}$ \\
2735 & 25.75 & $8.467 \times 10^{-26}$ & $6.046 \times 10^{-18}$ \\
2830 & 44.16 & $7.299 \times 10^{-26}$ & $2.873 \times 10^{-18}$ \\
2876 & 44.09 & $6.807 \times 10^{-26}$ & $1.724 \times 10^{-18}$ \\
2922 & 71.28 & $6.356 \times 10^{-26}$ & $1.010 \times 10^{-18}$ \\
2975 & 71.49 & $5.883 \times 10^{-26}$ & $4.980 \times 10^{-19}$ \\
3019 & 54.64 & $5.524 \times 10^{-26}$ & $2.606 \times 10^{-19}$ \\
3058 & 70.02 & $5.229 \times 10^{-26}$ & $1.587 \times 10^{-19}$ \\
\hline
\end{tabular}


angle $\theta_{0}$ is an average value for each station. The iteration was terminated at the 5 th because it was empirically determined that stopping at the 4th or 5th iteration is optimum in terms of the accuracy achievable and the computational time required. The ozone distribution shown in Figs. 4 and 5 were obtained with five iterations. The average residuals for all wavelengths at the 5 th iteration $\left\langle R^{(5)}\right\rangle$ were 2.9 percent (Point Mugu), 3.0 percent (Primrose), 3.6 percent (Panama), 2.5 percent (Barking Sands), initial of which had been respectively 7.7 percent, 10.2 percent, 9.7 percent and 7.3 percent. The error bars are shown only for the rocket profiles. Fairly large errors appear in the ozone profiles of rocket data. They are partially caused by the fact that the ozone density at each altitude is computed by differentiating column densities obtained with rocket optical ozonesonde. As mentioned in the introduction, this kind of technique using columnar amount enlarges the error of ozone profiles.

An estimate of error in the inversion of the satellite can be determined from Eqs. (8)-(10). The magnitudes of $E_{i}$ in Eq. (8) are around 1.0 (larger for shorter wavelength and smaller for longer wavelength) for eight wavelengths. In other words, a radiance error produces almost the same magnitude error in ozone number density. The expected instrument error of the NIMBUS 4 system is \pm 1.15 percent $\left(\delta_{\mathrm{e}}= \pm 1.15\right.$ percent). Representative figures for the error are shown in Figs. 6(a) and (b) in terms of ozone number density and mixing ratio, respectively. These figures were obtained from calculation using the residual $\left\langle R^{(5)}\right\rangle=3$ percent, which is the average for the four stations in Figs. 4 and 5. The standard profile $M$ in Fig. 2 is shown with the calculated error bars. These estimated error bars at each altitude indicate the average magnitude of errors of the inferred ozone distributions of Figs. 4 and 5. It is readily seen that in the region from 25 to $50 \mathrm{~km}$, errors are about \pm 4 percent $(\delta F= \pm 4$ percent), and the errors shown are the sum of the instrumental error of NIMBUS $4\left(\delta_{\mathrm{e}}= \pm 1\right.$ percent $)$ and the theoretical error $\left(\left\langle R^{(5)}\right\rangle \simeq 3\right.$ percent $)$. One should note here that the residual is treated as the theoretical error in Eq. (10), neglecting other theoretical errors. Above and below the 25 to $50 \mathrm{~km}$ region the errors increase inversely proportional to

$$
\sum_{i=1}^{8} P_{i j}
$$

which is the sum of the normalized weight function for the eight channels.

\subsection{Discussion}

As shown in Figs. 4 and 5, the profiles obtained for the BUV inversion and those from rocket ozonesondes agree very well at four stations in the altitude region below about $50 \mathrm{~km}$ (or $1 \mathrm{mb}$ ). The agreement between the two profiles (satellite and rocket), however, is not as good above $1 \mathrm{mb}$. There appears to be a systematic difference (i.e., the ozone distribution from the satellite is smaller than that from the rocket) above about $50 \mathrm{~km}$ at low latitudes, although the error bars are large in both profiles in the upper region. Unfortunately, we are unable to offer an explanation 


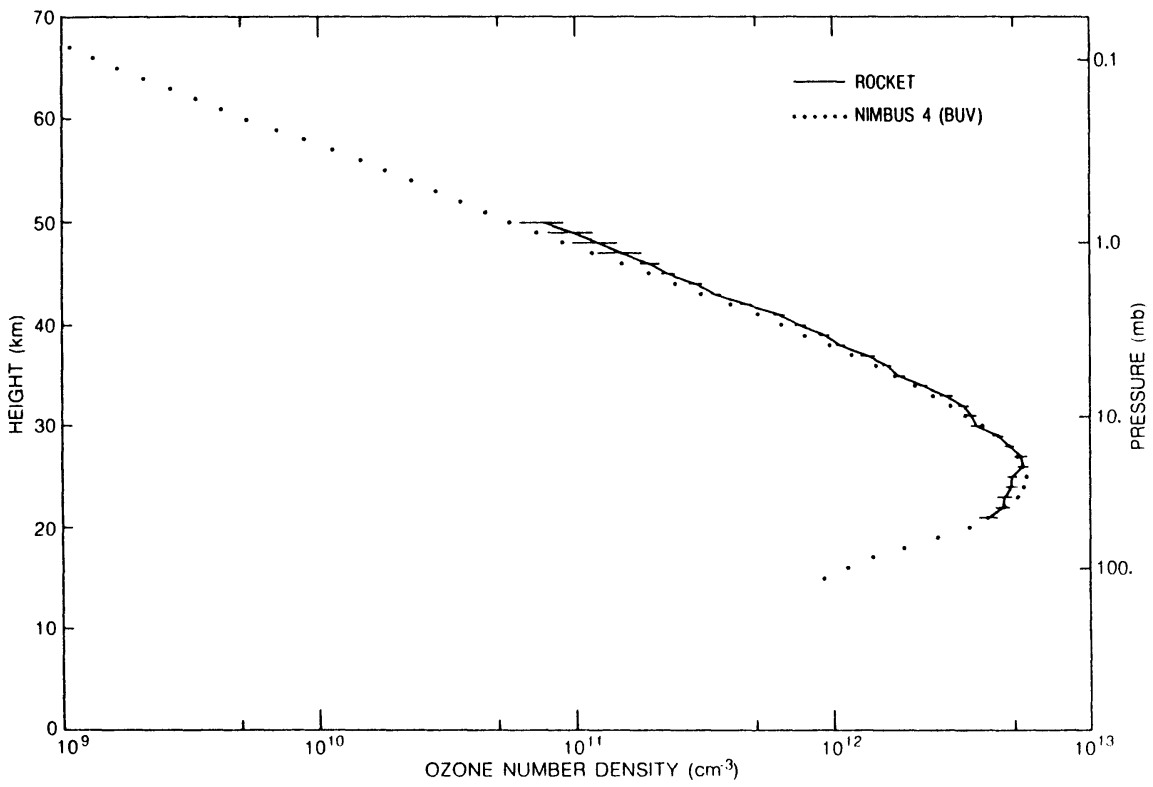

(a)

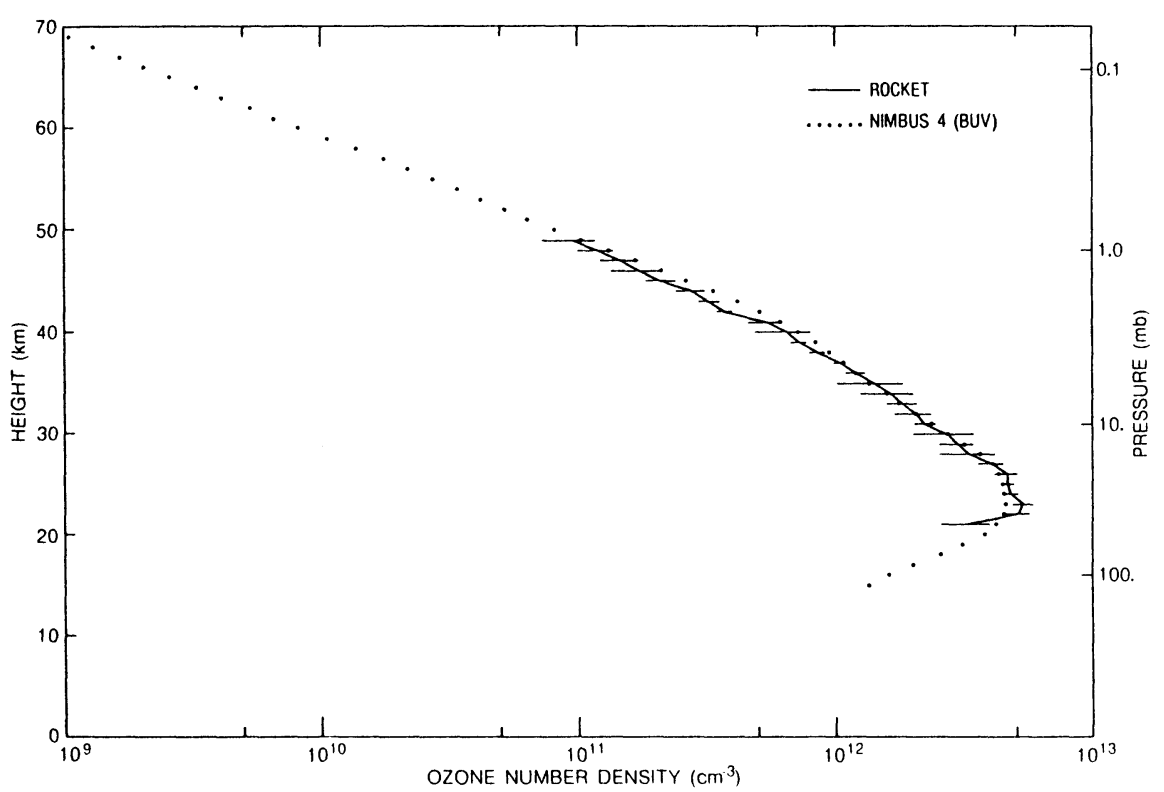

(b)

Fig. 4. 


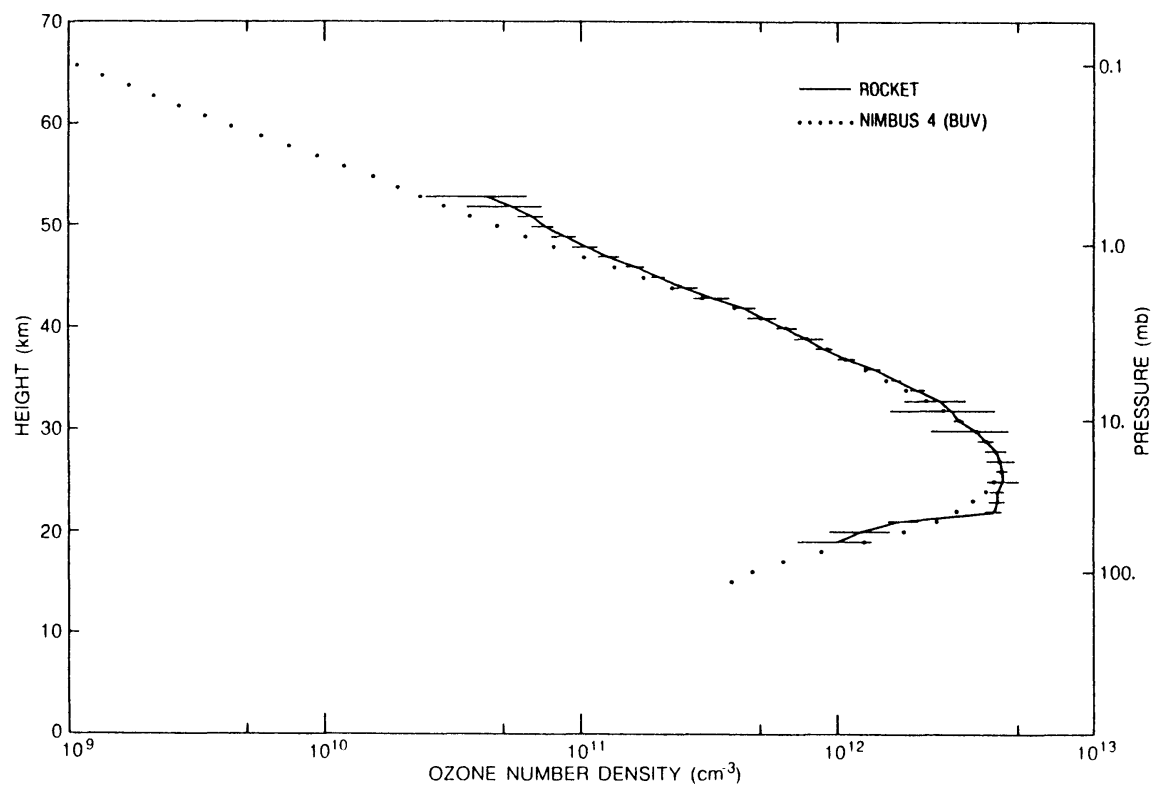

(c)

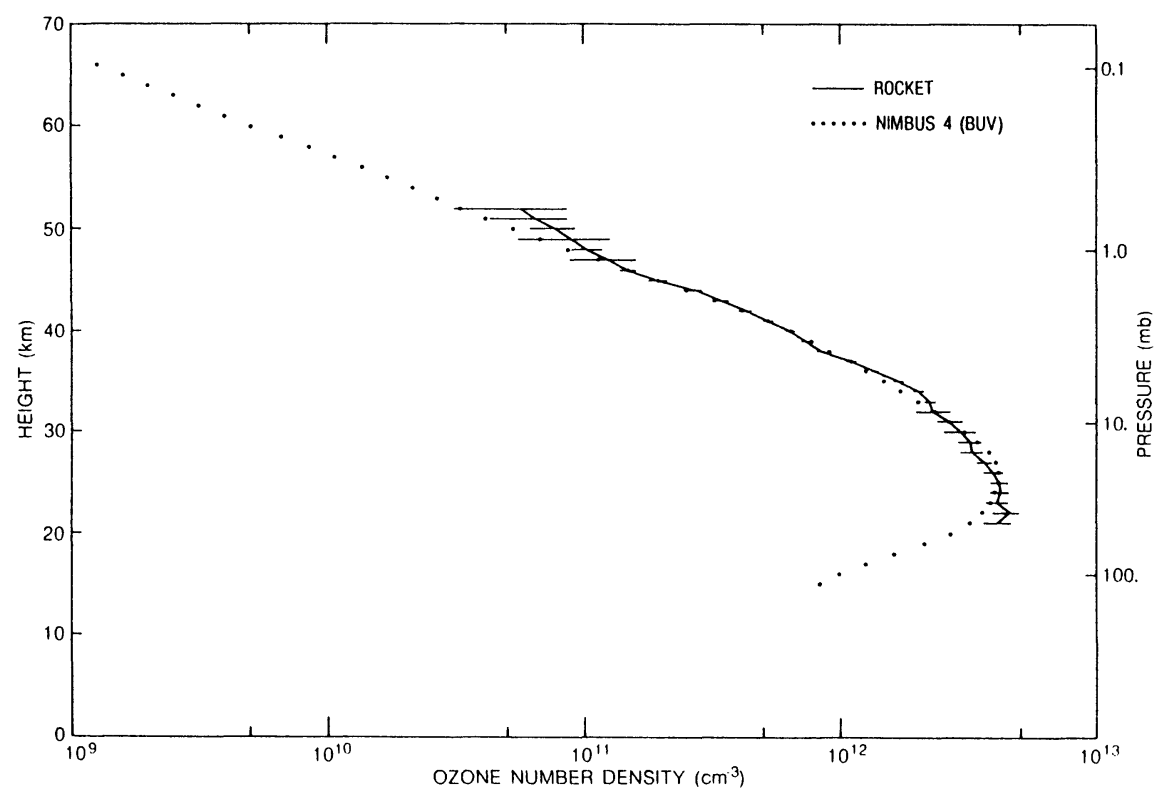

(d)

Fig. 4. Comparisons of the vertical distributions of ozone which were inferred from the BUV experiment on the NIMBUS 4 satellite with those obtained from rocket optical ozonesondes. Vertical distributions in terms of ozone number density are shown at four stations (a) Point Mugu $\left(33.9^{\circ} \mathrm{N}\right)$, (b) Primrose $\left(54.6^{\circ} \mathrm{N}\right)$, (c) Panama $\left(9.7^{\circ} \mathrm{N}\right)$, (d) Barking Sands $\left(22.7^{\circ} \mathrm{N}\right)$. 


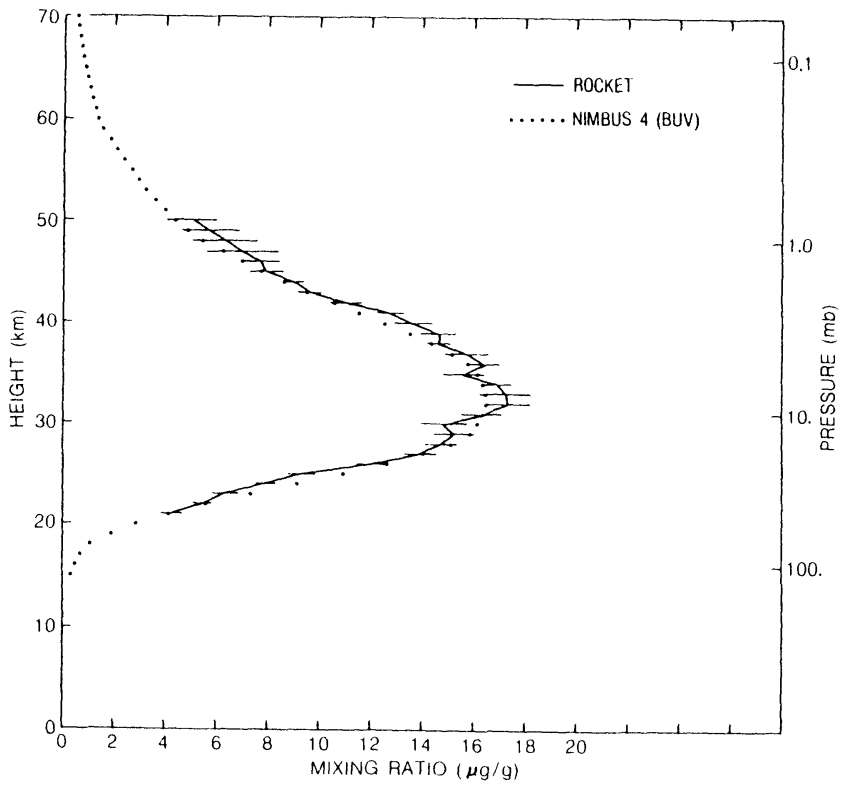

(a)

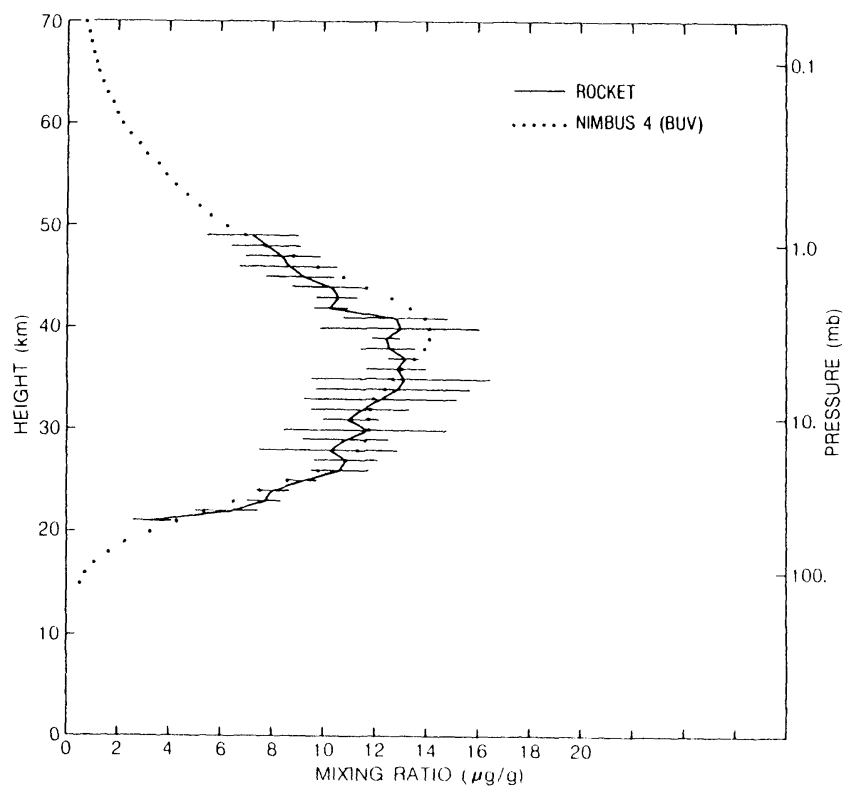

(b)

Fig. 5. 


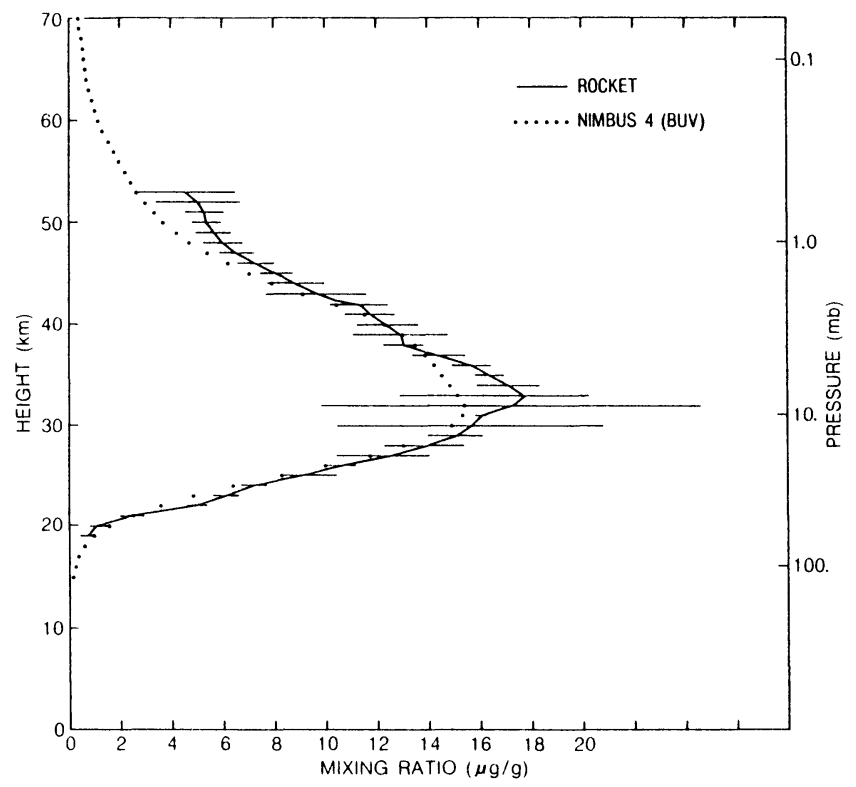

(c)

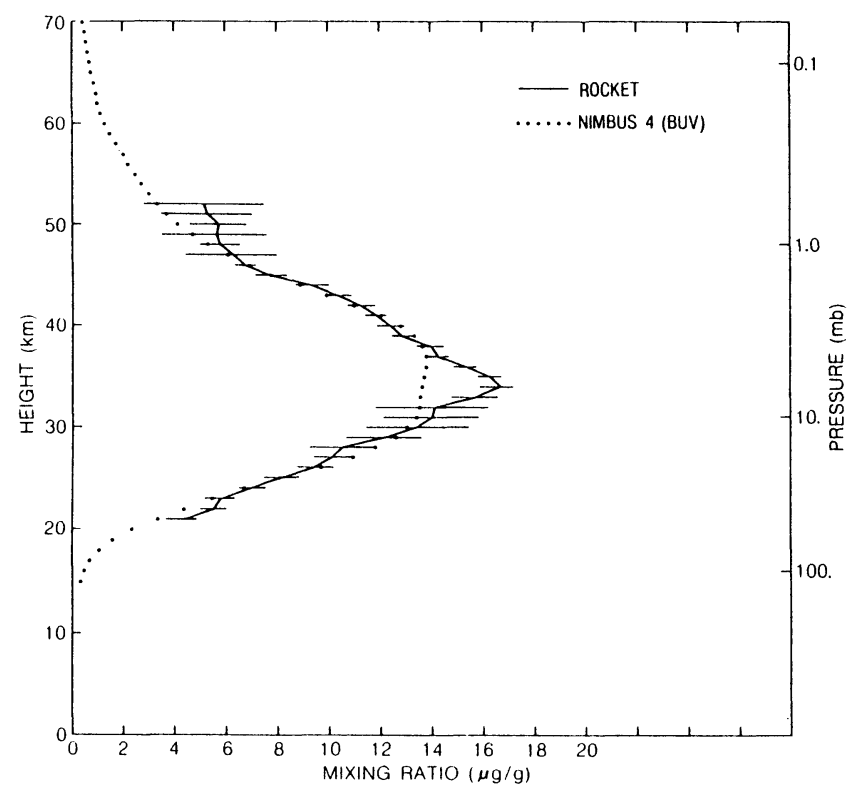

(d)

Fig. 5. Same as Fig. 4 except for the vertical distributions in terms of ozone mass mixing ratio. 
Table 2. Solar zenith angle, surface reflectivity and multiple scattering coefficient.

\begin{tabular}{ccccc}
\hline & Point Mugu & Primrose & Panama & Barking Sands \\
\hline$\theta_{0}$ & 13.95 & 65.81 & 26.54 & 34.78 \\
$A$ & 0.138 & 0.119 & 0.545 & 0.117 \\
$2975(\AA)$ & 1.018 & 1.009 & 1.140 & 1.028 \\
3019 & 1.285 & 1.066 & 1.712 & 1.336 \\
3058 & 1.660 & 1.305 & 2.152 & 1.697 \\
\hline
\end{tabular}

Note: Multiple scattering coefficients are shown in the lower column for three wavelengths as the value of $\left(1+C_{\mathrm{m}}\right)$.

for the difference at the present time.

The total ozone content obtained by the improved inversion method is given in Table 3. These total ozone values were obtained from an integration of the inferred profiles. The total ozone content derived from another NIMBUS 4 BUV experiment, in which total ozone column content is determined by the differential absorption method using two wavelength pairs separated by about $200 \AA$ (DAVE and MATEER, 1967), is also shown. Total ozone values derived from the two methods agree well. In general cases, the total ozone content obtained by the differential absorption method should give us better information about lower layer ozone content than the inversion method, because the former uses longer wavelengths which penetrate deeper. Actually, however, the total ozone content inferred by the differential absorption method depends on the assumed ozone profile. Inaccuracy in the assumed profile is thus reflected in the inferred total content. Total ozone content obtained by the differential absorption method is not accurate in the presence of clouds with high reflectivity at high altitude, as shown in Table 3, or when the solar zenith angle is very large. Therefore, if one uses these methods jointly, one can obtain better total ozone content as well as vertical distributions after iterations by the improved inversion method. If cloud-top height as well as the reflectivity is known, more accurate ozone profiles and total contents can be obtained. This is possible by means of polarization measurement of BUV (ARUGA et al., 1984).

If we do a computer simulation using profiles such as those shown in Figs. 4 and 5 , we get a residual $\left\langle R^{(5)}\right\rangle$ of 1 percent or less after five iterations. As mentioned above, however, the actual residual was about 3 percent for all stations. This means that the actual residual is not so much due to an insufficient number of iterations as it is to uncertainties in theoretical assumptions such as the ozone absorption coefficient, and the standard atmosphere or abnormal observational radiance errors. A large error in the first guess of the ozone profile in the region in which the magnitude of weight is small (lower and upper boundary regions) will also result in a large residual. It is to be noted that unknown instrument calibration errors can also increase the residual.

On the error bars calculation in this work, \pm 1 percent instrumental error and 


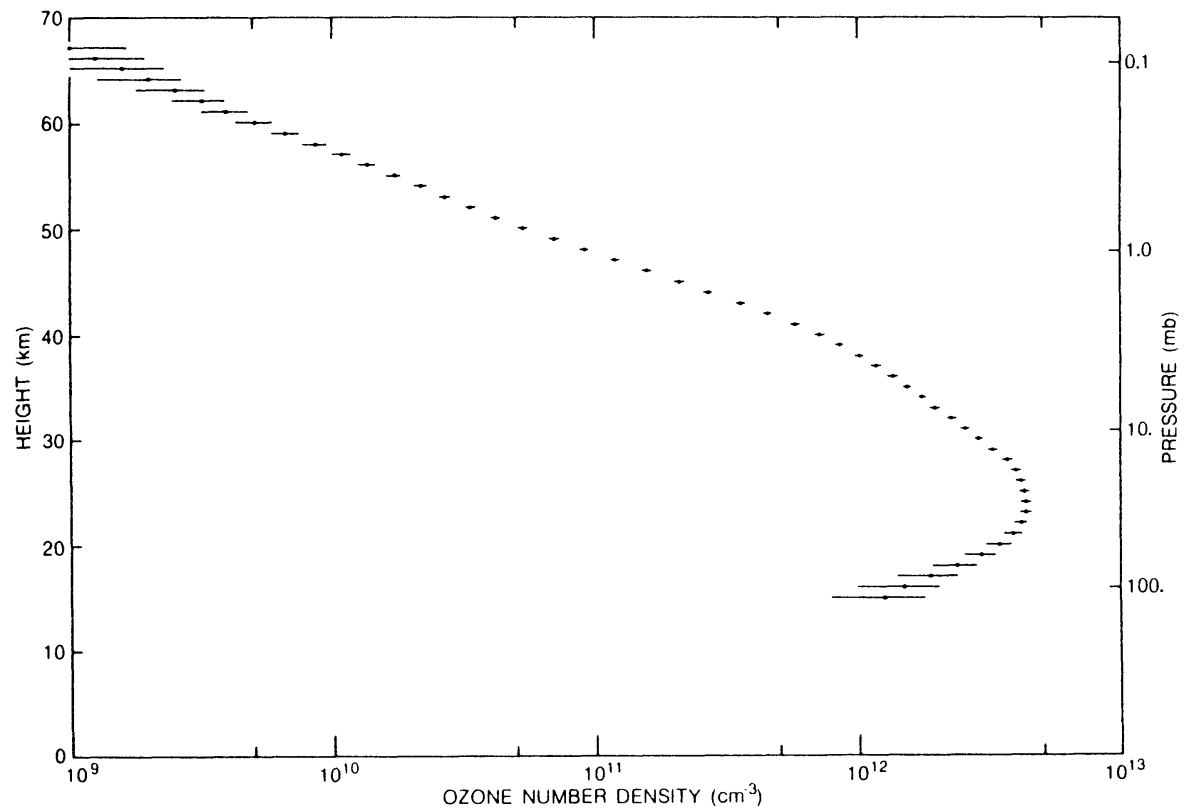

(a)

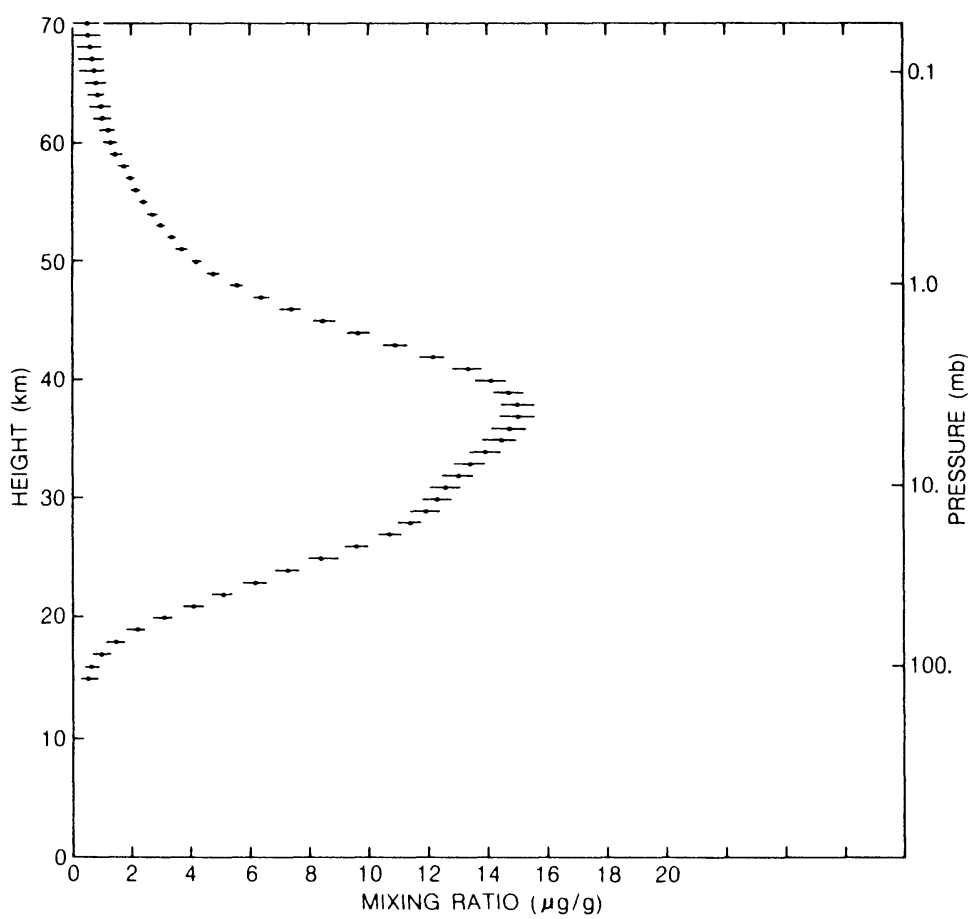

(b)

Fig. 6. An example of error bars for the inferred ozone profiles from BUV experiments using the inversion method. Midlatitude standard profiles with average error bars of four cases of Figs. 4 and 5 are shown as (a) ozone number density, (b) ozone mass mixing ratio. 
Table 3. Total ozone content (Atm-cm).

\begin{tabular}{ccccc}
\hline & Point Mugu & Primrose & Panama & Barking Sands \\
\hline BUV (this work) & 0.335 & 0.305 & 0.245 & 0.258 \\
BUV (differential & 0.328 & 0.311 & $0.227^{*}$ & 0.248 \\
\begin{tabular}{c} 
absorption) \\
\hline
\end{tabular} & & & & \\
\hline
\end{tabular}

*This value is not accurate because of high reflectivity.

\pm 3 percent residual error for $\delta_{\mathrm{t}}$ and $\delta_{\mathrm{e}}$ were taken into account. We do not think these are enough for experimental and theoretical errors in Eq. (10), for there are errors discussed above and others. One should take other errors into account as many as possible.

\section{Remarks for the Future Study}

\subsection{Selection of optimum set of wavelengths}

Residuals $R_{i}$ for the currently used wavelengths are generally smaller at shorter wavelengths and larger in longer wavelengths. This effect is caused by the crowding together of weighting functions in the shorter wavelength regions (see Fig. 3). It might be desirable to select the wavelengths so as to equalize the residuals at all of the wavelengths in order to optimize the accuracy for the profile inversion.

To select an optimum set of wavelengths, an investigation by computer simulations has been conducted. The simulations for selecting optimum band were addressed to the two basic terms: (1) test for influence of inferred ozone profile caused by errors of radiance of experimental or theoretical, (2) test of ozone profile retrieval assuming no errors. The results indicate that the best ozone profile yields when we choose wavelengths in a way where altitude separation of each weighting function's peak is proportional to half-width of the weighting function.

To show this principle more quantitatively, consider $i$-th wavelength, $\lambda_{i}$, altitude of weight's peak at this wavelength, $h_{i}$, and half-width of this weight, $w_{i}$. Further define distance of the weight peak altitudes between $i$ and $i+1$ as $d_{i, i+1}$ $\left(=h_{i}-h_{i+1}\right)$. Then the best condition is expressed by

$$
d_{i, i+1}=C \frac{w_{i}+w_{i+1}}{2}, \quad C=\text { const. }
$$

When we use 8 channels,

$$
\sum_{i=1}^{7} d_{i, i+1}=h_{1}-h_{8}
$$




$$
\sum_{i=1}^{7} C\left(\frac{w_{i}+w_{i+1}}{2}\right)=C\left(\frac{w_{1}}{2}+w_{2}+\cdots+w_{7}+\frac{w_{8}}{2}\right)
$$

then

$$
C=\left(h_{1}-h_{8}\right) /\left(\frac{w_{1}}{2}+w_{2}+\cdots+w_{7}+\frac{w_{8}}{2}\right)
$$

Example of weight peak altitude versus wavelength is shown in Fig. 7, where the solar zenith angle of $60^{\circ}$ and the mid-latitude $300 \mathrm{~cm}-\mathrm{STP}$ standard ozone profile are used as a representative. The weight peak altitudes of the current BUV band and of the optimum band obtained for the above conditions are also shown on the right side of Fig. 7.

Considering high altitude region, the standard ozone profiles (HILSENRATH et al., 1977) do not so change by latitude and total content variations, and hence the weighting function does not so depend on the standard ozone profiles. In this sense, one test profile is enough for this work. The weighting function, however, strongly depends on the solar zenith angle as shown in Fig. 8, so that the optimum band selection was considered for several solar zenith angles.

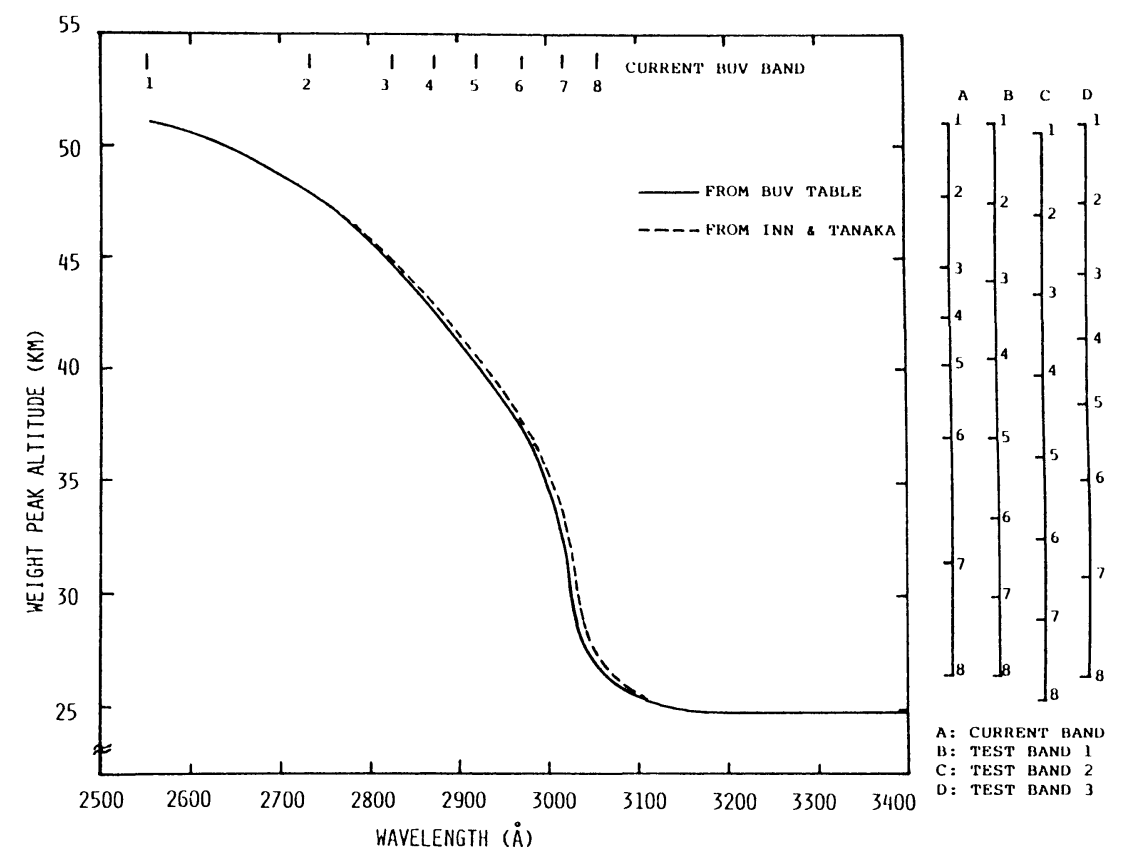

Fig. 7. Weight peak altitude variation at the BUV wavelength region. Altitudes of weight peak at the wavelengths of currently used band (A), some test bands (examples) (B)-(D), and the selected optimum band (which is one of test bands) (D), are shown on the right side. 


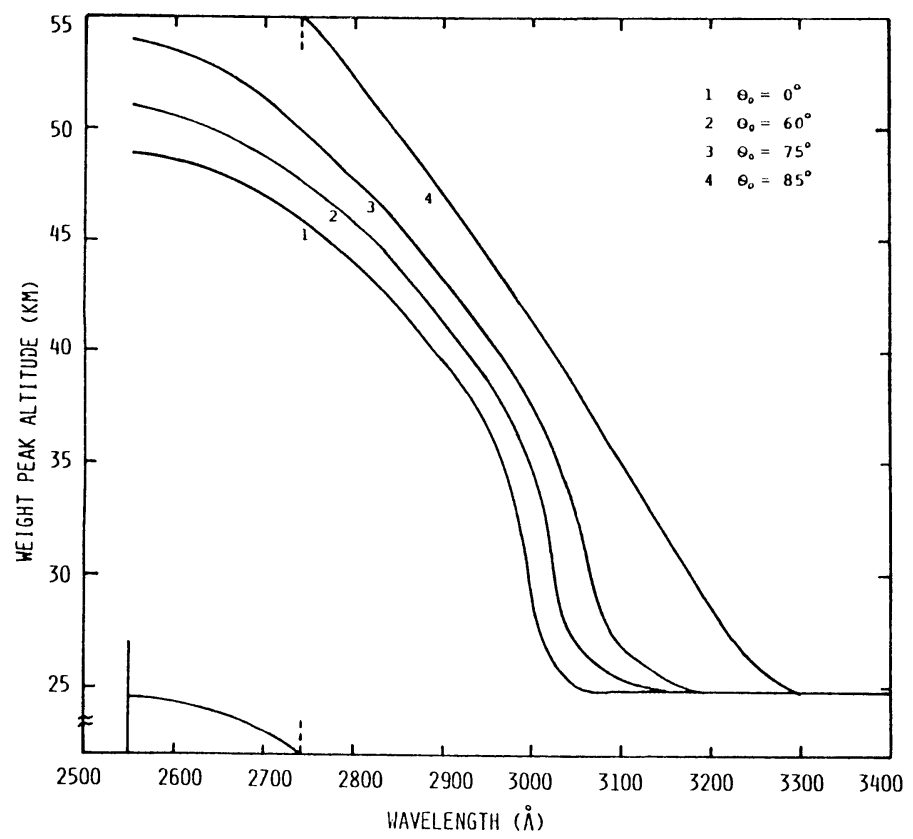

Fig. 8. Weight peak altitude variations when the solar zenith angle changes.

Table 4. Optimum wavelengths for the retrieval of ozone vertical profiles using the BUV satellite observation.

\begin{tabular}{ccccc}
\hline \multirow{2}{*}{ Channel } & \multicolumn{4}{c}{ Solar zenith angle $\left(\theta_{0}\right)$} \\
\cline { 2 - 5 } & $0^{\circ}$ & $60^{\circ}$ & $75^{\circ}$ & $85^{\circ}$ \\
\hline 1 & 2555 & 2555 & 2555 & 2555 \\
2 & 2755 & 2745 & 2725 & 2745 \\
3 & 2840 & 2835 & 2815 & 2810 \\
4 & 2900 & 2895 & 2880 & 2870 \\
5 & 2955 & 2950 & 2935 & 2925 \\
6 & 2985 & 2995 & 2985 & 2970 \\
7 & 3000 & 3020 & 3030 & 3015 \\
8 & 3060 & 3060 & 3060 & 3060 \\
extra & & & 3100 & 3105 \\
& & & & 3160 \\
& & & & 3210 \\
\hline
\end{tabular}


The result of optimum set of wavelengths is shown in Table 4. Wavelengths between $2555 \AA$ and $3060 \AA$ are selected with an accuracy of $5 \AA$. For large solar zenith angles, some additional wavelengths are useful for inferring lower ozone layer, since the weight peak altitude moves towards higher altitude region for the large $\theta_{0}$. One must slightly sift these wavelengths taking account of the influences by Fraunhofer lines and by emission lines of the terrestrial atmosphere such as from NO.

The optimum band, i.e., optimum set of wavelengths depends on the solar zenith angle, consequently one needs to select the wavelengths previously as an average or for the most frequent solar zenith angle, when each channel of equipment is fixed. Judging from Table 4 , for very large solar zenith angles of $75^{\circ} \sim 85^{\circ}$, the current BUV/SBUV band is fairly close to the optimum one. On the other hands, one can select an optimum set of wavelengths for a solar zenith angle in the process of inversion when the channels of equipment are not fixed but observed continuously.

\subsection{Other remarks}

In the presented inversion method, relative increment ozone density is used for a parameter in place of an absolute one, as defined in Eqs. (2) and (3). This technique enables us to infer ozone profile over wider range of altitude. This is, however, invalid when the BUV radiances are extremely large, because $y_{j}$ may be less than -1 , i.e., ozone number density is negative (unreal) in the extreme condition. (There is no trouble when the BUV radiances are extremely small since $y_{j}$ is positive in this condition.) To avoid the critical solution, an improved definition of $y_{j}$ is available in place of Eqs. (2) and (3) as follows:

$$
\mathrm{e}^{y_{\prime}}=\frac{N[j]}{\bar{N}[j]}, \quad j=1,2, \ldots, n
$$

or

$$
N[j]=\bar{N}[j] \mathrm{e}^{v_{j}}, \quad j=1,2, \ldots, n .
$$

Although linearity is not so good when $\left|y_{j}\right|$ is large, the same equation, $\mathrm{d} y_{j}=\mathrm{d} N[j] / \bar{N}[j]$ as from Eqs. (2) and (3) is derivable when $\left|y_{j}\right|$ is small. Therefore, as long as we use iteration, the usage of the above new definition

$$
y_{j} \equiv \mathrm{e}^{y_{j}}-1 \text {, }
$$

yields almost the same solution as from the original one avoiding the abnormal solution mentioned above. It also became clear from many analyses that the step 2 (a correction for nonlinearity) in the iteration process (see ARUGA and IGARASHI, 1976) can be generally cut off. 
A feature of the presented inversion method is to consider the hypothetic ozone profile and use the radiant sensitivity for relative increment of ozone number density in each sublayer as shown in Eqs. (4) and (5). The technique of solution by iteration is another feature. Owing to these features, ozone profiles are obtained with high accuracy over a wide range of altitude. Especially ozone profiles in the upper stratosphere can be determined more accurately than the generally used Laplace transform or pressure increment (PI) methods. The fact was confirmed by computer simulation, then global ozone distributions were obtained using NIMBUS 4 data (MAEDA et al., 1984). Recently the BUV satellite observation has begun also in Japan (SUZUKI et al., 1985). The satellite ozone observation by means of BUV seems to expand more worldwidely in the future. Judging from the results of this work and other studies conducted separately by the authors, the improved inversion method will be one of the most useful methods for determining ozone profiles. Furthermore the principle of this method will be applicable to other inversion problems of remote sensing in the future.

\section{Conclusion}

A new method for determining the vertical distribution of ozone in the upper atmosphere was presented in 1976. This method permits retrieval of vertical ozone profiles with high accuracy and over a wide range of altitude, and is thus suitable for global determination of ozone from satellite observation. The new method has been so improved that the error bars on ozone profiles, as well as the multiple-scattering correction, are taken into account.

In this paper the vertical distribution of ozone in the upper atmosphere is obtained by the use of the improved inversion method and the BUV spectral data of the NIMBUS 4 satellite. These profiles were compared with those obtained from rocket ozonesondes launched in conjunction with satellite overpasses. Good agreement is found between profiles inferred from satellite observations and those measured directly with rocket ozonesondes except for the region above $50 \mathrm{~km}$. There are systematic differences above $50 \mathrm{~km}$ at low latitudes, i.e., ozone concentrations obtained with the rocket are larger than those inferred from the satellite observations. This discrepancy should be examined in the future. Total ozone content obtained by this method also closely agrees with those inferred from another NIMBUS 4 BUV experiment using differential absorption. It seems that the fact that vertical ozone distributions were obtained with higher accuracy and over a wide range of altitude by this method, is due not only to the multiple-scattering correction in which the lower boundary effects were taken into account, but also to the selfconsistency of the weighting functions of the new inversion method. The results show that the method is clearly valid for determining the vertical distributions of atmospheric ozone on a global basis. It is also concluded that the total ozone content derived from this BUV inversion method is useful for comparison and improvement, since the total ozone content measured by the BUV differential absorption method is not accurate on some conditions. 
Judging from the interval of the weighting functions, the selection of wavelengths on NIMBUS 4 and 7 does not seem to be optimum. The use of optimum band is desirable in the future for BUV satellite observations, as the selection shown in this work demonstratively. Furthermore a logarithmically defined parameter of ozone increment in the inversion equation should be used when there is a possibility of extremely large radiances, i.e., extremely small ozone densities are inferred.

The results of this work and some studies separately conducted by the authors indicate that the improved inversion method will be one of the most useful methods for the ozone observation, and that the principle of this method should be applicable to other inversion problems in remote sensing.

We wish to thank Dr. A. Krueger for supplying rocket data, and Dr. R. McPeters for his help in processing satellite data, and Dr. K. Maeda, Dr. R. Stewart and Dr. P. K. Bhartia for their valuable advice, all in NASA Goddard Space Flight Center. We also wish to express our thanks to the members of the OPT project for their encouragement and advice during this work.

When the large part of this work was done, T. Aruga was NAS/NRC Research Associate under the support of NASA on leave from the Ministry of Posts and Telecommunications, Radio Research Laboratories, Koganei, Tokyo, Japan.

\section{REFERENCES}

Anderson, G. P., C. A. Barth, F. Cayla, and J. London, Satellite observations of the vertical ozone distribution in the upper stratosphere, Ann. Geophys., 25, 341-345, 1969.

Aruga, T. and T. Igarashi, Vertical distribution of ozone: A new method of determination using satellite measurements, Appl. Opt., 15, 261-272, 1976.

Aruga, T. and D. F. HeAth, Backscattered ultraviolet radiation from turbid and spherical atmosphere, J. Opt. Soc. Am., 68, 1434, 1978.

Aruga, T. and D. F. HeATH, Backscattered ultraviolet radiation: Effects of multiple scattering and the lower boundary of the atmosphere, Appl. Opt., 21, 3038-3046, 1982a.

Aruga, T. and D. F. Heath, Determination of vertical ozone distributions by spacecraft measurements using a limb-scan technique, Appl. Opt., 21, 3047-3054, 1982b.

Aruga, T., K. Maeda, and D. F. Heath, Feasibility of determining cloud-top heights using backscattered ultraviolet satellite observation technique, J. Appl. Meteor., 23, 824-831, 1984.

Chahine, M. T., Inverse problems in radiative transfer: Determination of atmospheric parameters, $J$. Atoms. Sci., 27, 960-967, 1970.

Conrath, B. J., R. A. Hanel, V. G. Kunde, and C. Prabhakara, The infrared interferometer experiment on Nimbus 3, J. Geophys. Res., 75, 5831-5857, 1970.

DAve, J. V. and C. L. MATEER, A preliminary study on the possibility of estimating total atmospheric ozone from satellite measurements, J. Atmos. Sci., 24, 414-427, 1967.

Farman, J. C., B. G. Gardiner, and D. J. Shanklin, Large losses of total ozone in Antarctica reveal seasonal $\mathrm{CLO}_{x} / \mathrm{NO}_{x}$ interaction, Nature, 315, 207-210, 1985.

Fleig, A. J., K. F. Krenk, P. K. Bhartia, D. Gordon, and W. H. Schneider, User's guide for the solar backscattered ultraviolet (SBUV) instrument first year ozone-S data set, NASA R. P. 1095, 1982.

Heath, D. F., C. L. Mateer, and A. J. Krueger, The Nimbus 4 backscatter ultraviolet (BUV) atmospheric ozone experiment-Two year's operation, Pure Appl. Geophys., 106-108, 1238-1254, 1973. 
Heath, D. F., A. J. Krueger, H. A. Roeder, and B. D. Henderson, The solar backscattered ultraviolet and total ozone mapping spectrometer (SBUV/TOMS) for Nimbus-G, Opt. Eng., 14, 323-331, 1975.

Hilsenrath, E., P. J. Dunn, and C. L. Mateer, Standard ozone profiles from balloon and rocket data for satellite and theoretical model input, Proc. CMUA Sessions IAGA/IAMAP Assembly, Seatle, Wash., August, 1977.

Iozenas, V. A., Determining the vertical ozone distribution in the upper atmosphere layers from satellite measurements of ultraviolet solar radiation scattered by the earth's atmosphere, Geomag. Aeron., 8 , 403-407, 1968.

Krueger, A. J., The mean ozone distribution from several series of rocket soundings to $52 \mathrm{~km}$ at latitudes from $58^{\circ} \mathrm{S}$ to $64^{\circ} \mathrm{N}$, Pure Appl. Geophys., 106-108, 1272-1280, 1973.

Krueger, A. J., D. F. Heath, and C. L. Matter, Variations in the stratospheric ozone field inferred from Nimbus satellite observations, Pure Appl. Geophys., 106-108, 1254-1263, 1973.

London, L., J. E. FREDERICK, and G. P. ANDERSON, Satellite observations of the global distribution of stratospheric ozone, J. Geophys. Res., 82, 2543-2556, 1977.

Maeda, K., D. F. Heath, and T. Aruga, North-south asymmetries of solar particle events in upper stratospheric ozone, Planet. Space Sci., 32, 857-870, 1984.

MATEER, C. L., A review of some aspects of inferring the ozone profile by inversions of ultraviolet radiance measurement, in The Mathematics of Profile Inversion, edited by L. Colin, pp. 2-25, NASA TM-X-62150, 1972.

PrabhaKara, C., Feasibility of determining atmospheric ozone from outgoing infrared energy, Mon. Wea. Rev., 97, 307-314, 1969.

RoDgERs, C. D., Retrieval of atmospheric temperature and composition from remote measurements of thermal radiation, Rev. Geophy. Sp. Phys., 14, 609-624, 1976.

Singer, S. F. and R. C. Wentworth, A method for the determination of the vertical ozone distribution from a satellite, J. Geophys. Res., 62, 299-308, 1957.

SMITH, W. L., Iterative solution of the radiative transfer equation for the temperature and absorbing gas profile on an atmosphere, Appl. Opt., 9, 1993-1999, 1970.

Stolarski, R. S., A. J. Krueger, M. R. Schoeberl, R. D. McPeters, P. A. Newman, and J. C. ALPERT, Nimbus-7 satellite measurements of the springtime Antarctic ozone decrease, Nature, 322, $808-811,1986$.

Suzuki, K., T. Ogawa, and S. Kadokura, The BUV experiment for satellite "OHZORA", J. Geomag. Geoelectr., 37, 225-236, 1985.

TwOMEY, S., On the deduction of the vertical distribution of ozone by ultraviolet spectral measurements from a satellite, J. Geophys. Res., 66, 2153-2162, 1961.

TwOMEY, S., The application of numerical filtering to the solution of integral equations encountered in indirect sensing measurements, J. Franklin Inst., 279, 95-109, 1965.

Valley, S. L., (Ed.), Handbook of Geophysics and Space Environments, McGraw-Hill, New York, 1965.

YARGER, D. N., An evaluation of some methods of estimating the vertical atmospheric ozone distribution from the inversion of spectral ultraviolet radiation, J. Appl. Meteor., 9, 921-928, 1970. 
Appendix: Multiple Scattering Coefficients for Some Representative Ozone Profiles

\begin{tabular}{|c|c|c|c|c|c|c|c|c|c|c|}
\hline \multirow{2}{*}{$\theta_{0}$} & \multirow{2}{*}{$A$} & \multicolumn{3}{|c|}{$\mathrm{L} 250$} & \multicolumn{3}{|c|}{ M300 } & \multicolumn{3}{|c|}{$\mathrm{H} 400$} \\
\hline & & $2975 \AA$ & $3019 \AA$ & $3058 \AA$ & $2975 \AA$ & $3019 \AA$ & $3058 \AA$ & $2975 \AA$ & $3019 \AA$ & $3058 \AA$ \\
\hline \multirow{5}{*}{$0^{\circ}$} & 0.00 & 1.07 & 1.49 & 1.94 & 1.03 & 1.31 & 1.60 & 1.01 & 1.10 & 1.30 \\
\hline & 0.25 & 1.08 & 1.64 & 2.20 & 1.03 & 1.38 & 1.75 & 1.01 & 1.11 & 1.39 \\
\hline & 0.50 & 1.08 & 1.82 & 2.47 & 1.03 & 1.47 & 1.92 & 1.01 & 1.13 & 1.49 \\
\hline & 0.75 & 1.09 & 2.02 & 2.78 & 1.03 & 1.57 & 2.13 & 1.01 & 1.15 & 1.61 \\
\hline & 1.00 & 1.10 & 2.26 & 3.15 & 1.03 & 1.71 & 2.40 & 1.01 & 1.17 & 1.76 \\
\hline \multirow{5}{*}{$40^{\circ}$} & 0.00 & 1.03 & 1.40 & 1.93 & 1.02 & 1.24 & 1.57 & 1.01 & 1.07 & 1.27 \\
\hline & 0.25 & 1.04 & 1.53 & 2.17 & 1.02 & 1.29 & 1.73 & 1.01 & 1.07 & 1.33 \\
\hline & 0.50 & 1.04 & 1.67 & 2.41 & 1.02 & 1.35 & 1.89 & 1.01 & 1.08 & 1.41 \\
\hline & 0.75 & 1.04 & 1.82 & 2.68 & 1.02 & 1.42 & 2.09 & 1.01 & 1.09 & 1.50 \\
\hline & 1.00 & 1.05 & 2.01 & 3.02 & 1.02 & 1.51 & 2.33 & 1.01 & 1.10 & 1.59 \\
\hline \multirow{5}{*}{$60^{\circ}$} & 0.00 & 1.01 & 1.21 & 1.74 & 1.01 & 1.11 & 1.42 & 1.01 & 1.04 & 1.15 \\
\hline & 0.25 & 1.01 & 1.25 & 1.90 & 1.01 & 1.12 & 1.52 & 1.01 & 1.04 & 1.17 \\
\hline & 0.50 & 1.01 & 1.30 & 2.06 & 1.01 & 1.14 & 1.62 & 1.01 & 1.04 & 1.20 \\
\hline & 0.75 & 1.01 & 1.35 & 2.24 & 1.01 & 1.16 & 1.75 & 1.01 & 1.04 & 1.23 \\
\hline & 1.00 & 1.01 & 1.43 & 2.51 & 1.01 & 1.18 & 1.89 & 1.01 & 1.04 & 1.27 \\
\hline \multirow{5}{*}{$70^{\circ}$} & 0.00 & 1.01 & 1.08 & 1.48 & 1.01 & 1.04 & 1.23 & 1.01 & 1.03 & 1.08 \\
\hline & 0.25 & 1.01 & 1.09 & 1.55 & 1.01 & 1.05 & 1.27 & 1.01 & 1.03 & 1.09 \\
\hline & 0.50 & 1.01 & 1.10 & 1.63 & 1.01 & 1.05 & 1.32 & 1.01 & 1.03 & 1.10 \\
\hline & 0.75 & 1.01 & 1.11 & 1.73 & 1.01 & 1.06 & 1.38 & 1.01 & 1.03 & 1.11 \\
\hline & 1.00 & 1.01 & 1.13 & 1.85 & 1.01 & 1.06 & 1.43 & 1.01 & 1.03 & 1.12 \\
\hline \multirow{5}{*}{$80^{\circ}$} & 0.00 & 1.01 & 1.03 & 1.13 & 1.01 & 1.03 & 1.06 & 1.01 & 1.02 & 1.05 \\
\hline & 0.25 & 1.01 & 1.03 & 1.14 & 1.01 & 1.03 & 1.07 & 1.01 & 1.02 & 1.05 \\
\hline & 0.50 & 1.01 & 1.03 & 1.15 & 1.01 & 1.03 & 1.07 & 1.01 & 1.02 & 1.06 \\
\hline & 0.75 & 1.01 & 1.03 & 1.16 & 1.01 & 1.03 & 1.08 & 1.01 & 1.02 & 1.06 \\
\hline & 1.00 & 1.01 & 1.03 & 1.17 & 1.01 & 1.03 & 1.08 & 1.01 & 1.02 & 1.06 \\
\hline \multirow{5}{*}{$90^{\circ}$} & 0.00 & 1.01 & 1.03 & 1.03 & 1.01 & 1.03 & 1.05 & 1.01 & 1.01 & 1.05 \\
\hline & 0.25 & 1.01 & 1.03 & 1.04 & 1.01 & 1.03 & 1.05 & 1.01 & 1.01 & 1.05 \\
\hline & 0.50 & 1.01 & 1.03 & 1.04 & 1.01 & 1.03 & 1.05 & 1.01 & 1.01 & 1.06 \\
\hline & 0.75 & 1.01 & 1.03 & 1.04 & 1.01 & 1.03 & 1.05 & 1.01 & 1.01 & 1.06 \\
\hline & 1.00 & 1.01 & 1.03 & 1.05 & 1.01 & 1.03 & 1.05 & 1.01 & 1.01 & 1.06 \\
\hline
\end{tabular}

Note: The value of $\left(1+C_{\mathrm{m}}\right)$ which is used in Eqs. (6) and (7), is shown for the three profiles in Fig. 2. The $\theta_{0}$ is solar zenith angle and $A$ is albedo of the earth surface. The multiple scattering coefficients were calculated by the method of ARUGA et al. (1982a). One can get good approximation for intermediates of the parameters (including wavelengths) by the interpolation. 